\title{
O desafio do fazer teológico em tempos de pandemia
}

\author{
The challenge of doing theology \\ in times of pandemic
}

\author{
Valdir Stephanini \\ Julio Cezar de Paula Brotto
}

\section{Resumo}

Este artigo se propõe a fazer uma reflexão sobre o desafio de fazer Teologia num tempo de crise vivida pela humanidade em virtude da pandemia da COVID-19. O objetivo central do artigo é mostrar que num tempo de pandemia como o que vive a humanidade desde o início do ano de 2020, todos os segmentos da sociedade precisam se manifestar, dando sua contribuição para a superação da crise e para a pavimentação de um novo mundo que pode ser construído a partir da pandemia. A questão que o artigo tenta responder é como propor abordagens teológicas que sejam relevantes e que façam a diferença diante da crise aguda, vivida pela humanidade com a pandemia do novo coronavírus, ou ainda, que tipo de Teologia pode ser feita de forma a contribuir para o enfrentamento dessa situação tão desesperadora para toda a humanidade. $\mathrm{O}$ artigo propõe uma abordagem panorâmica sobre o que significa viver num tempo de pandemia, pontuando os perigos e as oportunidades que esse momento representa para a humanidade. Apresenta alguns aspectos que envolvem o processo do fazer teológico. Por fim, esboça um possível perfil das Teologias desejáveis para esse momento, em virtude da pandemia da COVID-19.

Palavras-chaves: Teologia. Pandemia. Desafio. Coronavírus. 


\begin{abstract}
This article proposes to reflect on the challenge of doing Theology in a time of crisis experienced by humanity due to the pandemic of COVID-19. The main objective of the article is to show that in a time of a pandemic like that experienced by humanity since the beginning of the year 2020, all segments of society need to demonstrate, making their contribution to overcoming the crisis and paving a new world that can be built from the pandemic. The question that the article tries to answer is how to propose theological approaches that are relevant and that make a difference in the face of the acute crisis experienced by humanity with the new coronavirus pandemic, or even what kind of theology can be done in order to contribute to face this situation so desperate for all humanity. The article proposes a panoramic approach to what it means to live in a time of pandemic, highlighting the dangers and opportunities that this moment represents for humanity. Points some aspects that involve the theological making process will be presented. Finally, it outlines a possible profile of theologies desirable for that moment, due to the COVID-19 pandemic.
\end{abstract}

Keyword: Theology. Pandemic. Challenge. Coronavirus.

\title{
Introdução
}

É público e notório que vivemos um momento ímpar na sociedade contemporânea, jamais vivido antes, nos últimos 100 anos. Um tempo com muitos desafios que requer de todos os segmentos da sociedade uma profunda reflexão, adaptação e redefinição de conceitos e de estratégias de sobrevivência.

A pandemia do novo coronavírus tem atingido milhões de pessoas, infectando-as e levando-as a óbito, deixando outros milhões enlutadas, órfãs e viúvas. Além disso, agrava-se a crise econômica, engrossando as fileiras dos desempregados, alta na inflação com subida desenfreada nos preços de alimentos básicos e nos combustíveis, o que afeta diretamente toda a sociedade.

No dizer de Jon Sobrino, é nesses momentos de crise aguda vividos pela humanidade que soa a pergunta: onde está Deus? ${ }^{1}$ É com este cenário que

${ }^{1}$ SOBRINO, J., Onde está Deus? 
teólogos e teólogas precisam conviver e é para essa sociedade que se apresenta o desafio de fazer Teologia de maneira relevante, de tal forma que venha fazer diferença na vida das pessoas e contribuir para a superação da crise generalizada vivida, não por um país, mas por toda a humanidade.

O objetivo central do artigo é mostrar que num tempo de pandemia como o que vive a humanidade desde o início do ano de 2020, todos os segmentos da sociedade precisam se manifestar, dando sua contribuição para a superação da crise e para a pavimentação de um novo mundo que pode ser construído a partir da pandemia. Nesse contexto, a Teologia não pode ficar omissa, mas oferecer sua contribuição para a sociedade no sentido de fortalecer a fé, amenizar o sofrimento e alimentar a esperança no coração das pessoas que sofrem com a pandemia e todos os seus desdobramentos.

A pergunta levantada neste artigo é como fazer Teologia num tempo tão difícil como este, de tal forma a suprir as demandas provenientes da pandemia, ou, que tipo de Teologia precisa ser feita para que cumpra esse propósito. Para tanto, depois de uma visão panorâmica do que representa viver num tempo de pandemia, com seus temores e oportunidades, serão pontuados alguns aspectos do processo de fazer Teologia, culminando com a apresentação de pistas sobre quais abordagens teológicas seriam necessárias para que a Teologia cumpra sua função num tempo de pandemia.

\section{O que significa viver num contexto de pandemia}

O planeta Terra já vivia, no início deste século, um momento de grande crise e que pode também reforçar todo o processo de mudança de época que vem sendo experimentado no final do século XX e início do século XXI. A humanidade vivencia um tempo histórico que não é nem ordinário e nem raro. A humanidade vivencia uma mudança de época. Uma mudança genérica que afeta a vida de maneira plena. Não é um evento raro, porque a humanidade já experimentou mudanças de épocas em outras situações. Por outro lado, não pode ser entendido como um evento ordinário, porque uma mudança de época não acontece com constância. ${ }^{2}$

Neste momento que a humanidade atravessa uma mudança de época, diagnosticada de formas diferentes e até antagônicas, com diferentes cosmovisões que advogam sua verdade muitas vezes de forma absoluta

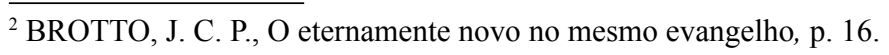


não raras vezes fundamentalista, as Igrejas Cristãs precisam responder ao desafio de falar de Deus. ${ }^{3}$

A presença de um vírus denominado coronavírus derrubou todas as estruturas socialmente construídas. O Ser humano, como entende Peter Berger, necessita de um ambiente social ordenado. ${ }^{4}$ Porém, o que se pode verificar neste período, de janeiro 2020 até junho de 2021, em todo o mundo, é uma desestruturação social sem precedentes na história da humanidade.

As relações sociais simbólicas sofrem abalos que levam todos os setores da sociedade a sentirem-se em uma verdadeira experiência da anomia. Registre-se que anomia neste momento é tomada no estrito sentido proposto por Durkheim para apresentar um estado social caótico, tumultuado, no qual se afrouxa a coesão e coerção moral sobre os indivíduos, levando-os à falta de regras e ao delito. Quando o sociólogo francês utiliza o termo em questão, ele busca sua origem etimológica no radical grego nomos - lei moral e costume - para definir anomia como a ausência de leis reguladoras. ${ }^{5}$ Essa anomia gera medo que toma conta da sociedade, desequilibrando as relações sociais voltadas para manter o mundo em ação. As estruturas sociais estão enfrentando um momento de caos.

Na percepção de Berger, "a constante possibilidade do terror anômico torna-se atual sempre que as legitimações que obscurecem esta precariedade são ameaçadas ou entram em colapso". ${ }^{6}$ Em momentos de crise intensa, como a humanidade está enfrentando, é muito mais complexo o exercício de legitimação e plausibilidade do sentido, por estarem fragilizadas as práticas normais propostas "a silenciar dúvidas e prevenir lapsos de convicção".

Com a chegada impetuosa do coronavírus no cenário mundial, ressurge junto com este estado de anomia, com força sem precedentes o medo, que ronda nações, cidades, famílias, pessoas e os grupos religiosos. Daniel Teixeira propõe que esta seja uma ocasião de "repensar radicalmente nossas práticas e modos de estar no mundo, quando mais do que nunca o indivíduo como categoria não dá conta dos seres sociais que somos". ${ }^{8}$

\footnotetext{
${ }^{3}$ BROTTO, J. C. P., O eternamente novo no mesmo evangelho, p. 17.

${ }^{4}$ BERGER, P. L., A construção social da realidade, p. 141.

${ }^{5}$ DURKHEIM, É., Da divisão do trabalho social, p. 367.

${ }^{6}$ BERGER, P. L., A construção social da realidade, p. 141.

${ }^{7}$ BERGER, P. L., Rumor de anjos, p. 66.

${ }^{8}$ TEIXEIRA, D. B., O novo coronavírus e as ecologias da plantation.
} 


\subsection{Temores provenientes do Coronavírus}

O que testemunhamos em muitas nações é o que o antropólogo Bruno Latour já em 2019 definiu como: "o sentimento de perder o mundo, agora, é coletivo". ${ }^{9}$ Latour mencionava não o coronavírus, mas as condições climáticas e a percepção de boa parte da população mundial em razão da chamada mudança climática, que este artigo se apropria porque certamente pode ser aposto à atual calamidade epidemiológica. Destaca Latour:

Antes, a angústia que a natureza nos causava vinha do fato de que éramos pequenos demais, e a natureza era imensa. Agora temos o mesmo tamanho, influímos em como a Terra se comporta. E é desorientador, por exemplo, para os jovens que se manifestam [contra a mudança climática]. Da extrema esquerda à extrema direita, todas as posições políticas estão marcadas pela angústia. ${ }^{10}$

Assim como Latour fala em sentimento de "perda do mundo", outros mencionam "tempo de incertezas" ou "estado de medo". Em um sentido muito acertado é possível reafirmar que a humanidade foi pega de surpresa com essa crise, e o pior é que está descobrindo dia a dia que os governos e a população estão despreparados para lidar com esta emergência. Para muitos, há esperança de que este seja um período de redescobrir a intimidade familiar, valores como diálogo e fraternidade. Contudo, a família pode vir a ser um espaço intolerante e de raiva ou acusações mútuas. Estar fora de casa gerava equilíbrio. Logo, é preciso investir intelectual e emocionalmente para colocar de lado os déficits relacionais familiares. A atmosfera de intolerância nas relações diárias, a partir do distanciamento físico imposto pelo coronavírus pode gerar desequilíbrios e tensões que eram atenuados com as escapadas para o mundo exterior.

Outro aspecto que gera tensão é o risco crescente de xenofobia. Trata-se do "medo do estrangeiro, da xenofobia, que impulsiona a erigir barreiras e muros, do medo de tudo que vem de fora, e que obriga as pessoas a fecharemse em seus nichos, a imunizar-se e proteger-se". ${ }^{11} \mathrm{E}$ em tempos de pandemia o fechamento de fronteiras, a intolerância com pessoas provenientes de deter-

\footnotetext{
${ }^{9}$ BASSETS, M., Bruno Latour.

${ }^{10}$ BASSETS, M., Bruno Latour.

${ }^{11}$ DI CESARE, D., Anche per lo stato d'eccezione la paura è un boomerang.
} 
minadas regiões do mundo, agrava o sofrimento daqueles e daquelas que são acometidos/as pela doença. $\mathrm{O}$ medo de que a vacina não chegue a tempo, de ser infectado/a, de que o sistema de saúde entre em colapso, de perder pessoas queridas num tempo em que nem mesmo os funerais podem ser realizados dentro da normalidade.

\subsection{As possibilidades oferecidas pelo coronavírus}

O COVID-19 não apresenta somente temores, mas oferece também oportunidades especiais para este tempo. Pode-se afirmar que é um tempo kairótico, formidável, que pode permitir reflexão para as religiões, igrejas e todas as formas de religiosidades no mundo. É um tempo que deveria gerar humildade.

Do ponto de vista de nossa angústia, o coronavírus não poderia ter um
nome melhor: ele nos tira do trono de nós mesmos e coloca a coroa de
nossas vidas em sua justa dimensão. É a coroa de espinhos que convoca
uma experiência escassa em nossa época: a humildade. Diante desta
pequena e destrutiva força da natureza, nosso narcisismo se dobra como
um vassalo encurralado. Apesar de dolorosa como um espinho na alma,
esta pode ser uma experiência profundamente transformadora. Descobrir
que podemos muito menos do que pensamos, aceitar o imponderável que
nos governa e acolher com humildade o que ainda não dominamos pode
ser muito benéfico. Pode ser uma verdadeira terapia para aqueles que
precisam descansar a cabeça do peso de sua coroa de espinhos narcísicos. ${ }^{12}$

Certamente a pandemia trouxe também novas oportunidades para que as pessoas aprendam a viver com mais simplicidade e menos apegados aos bens materiais; a valorizar os gestos de afeto e de carinho, impossibilitados pela pandemia; se reinventarem para conseguirem a renda necessária para a sobrevivência; redescobrir o ambiente da casa onde se habita; conviver mais próximas com as pessoas da família; utilizar das redes sociais para o compartilhamento de ideias e de produtos; usar as novas tecnologias para fins de trabalho e de estudos, enfim, são muitas as possibilidades provenientes de um tempo tão difícil ocasionado pela pandemia do novo coronavírus. Na próxima seção, será feita uma rápida abordagem sobre o processo do fazer teológico.

${ }^{12}$ DUNKER, C., Coroa de Espinhos. 


\section{Os processos do fazer teológico}

Fazer Teologia sempre foi e sempre será um grande desafio para aqueles/as que desejam compreender sobre Deus e o seu agir no mundo. Embora existam métodos diferentes utilizados por teólogos e teólogas nos mais diferentes contextos históricos e geográficos, é comum pensar no fazer teológico partindo da fé.

Falando sobre o fazer teológico, Afonso Murad afirma que:

A Teologia parte da fé, é feita com o olhar da fé e resulta em um saber que visa tornar a fé mais lúcida, para que as Igrejas cristãs desempenhem melhor sua missão evangelizadora. Recorde-se de que a fé aqui não é compreendida somente como confiança em Deus, mas sim nas suas quatro dimensões, que tocam afinadas como as cordas de um cavaquinho: entrega ao Senhor, conhecimento do que ele nos revela, prática do amor solidário e vivência da esperança. ${ }^{13}$

Partindo do pensamento de Tomás de Aquino, afirmando que o objeto material da Teologia é Deus, Murad advoga que "a matéria-prima da Teologia é Deus, como se revelou na história e é narrado na Bíblia". ${ }^{14}$ Sendo assim, será pertinente refletir sobre o grande desafio que é fazer Teologia em tempos de pandemia, assunto que será abordado na última seção deste artigo.

Zabatiero, por sua vez, menciona quatro características básicas para que um conteúdo seja considerado Teologia: hermeneuticidade, tem a função de interpretar a bíblia, a história, a realidade; criticidade ou discernimento, capaz de questionar a si mesma, as comunidades cristãs e a sociedade de um modo geral; praticidade, entendendo que o fazer teológico precisa partir da prática a fim de vencer as especulações dogmáticas e atrelar-se à vida e publicidade, que aconteça em espaços públicos, não somente na esfera privada, capaz de dialogar com os mais diferentes segmentos da sociedade. ${ }^{15}$ Segundo Zabatiero:

É exatamente este o papel profético e testemunhal da geologia cristã. Dar voz à comunidade da fé, libertada do fundamentalismo, comunidade que, pela fé no Messias, olha para o mundo com olhos compassivos e solidários, não se deixando contaminar com a indiferença do olhar sistêmico. A

${ }^{13}$ MURAD, A., A casa da Teologia, p. 27.

${ }^{14}$ MURAD, A., A casa da Teologia, p. 29.

${ }^{15}$ ZABATIERO, J. P., Para um método teológico, p. 23. 
publicidade da Teologia consiste em fazer com que a lâmpada do corpo seja clara e iluminadora, conforme ensinava Jesus no sermão do Monte. É através da dimensão pública da Teologia que as comunidades cristãs enfrentam a tentação de reduzir a missão ao crescimento da comunidade eclesial ou da instituição eclesiástica. Ao reconhecer sua dimensão publica, as comunidades que praticam a missão refletem teologicamente e se percebem como meios e não como fins no projeto de Deus. Na linguagem da Teologia da missão integral e da Teologia da libertação, a publicidade da Teologia faz com que as igrejas reconheçam que estão a serviço do Reino de Deus, e não de si mesmas, que estão a serviço de toda a criação e não apenas da religião cristã. ${ }^{16}$

Pensar na dimensão pública da Teologia será de extrema relevância ao se falar em como fazer Teologia num tempo em que toda a sociedade vive o dilema do enfrentamento de uma pandemia que assola toda a humanidade.

João Batista Libânio e Afonso Murad afirmam que "se se quer percorrer o movimento interno da Teologia, dois caminhos se apresentam. Pode-se partir do teólogo que vai construindo a Teologia até chegar a seu objeto fundamental - Deus - ou da fonte mesma da Teologia - Deus - até chegar ao teólogo". ${ }^{17}$

Por sua vez, a Teologia da Libertação parte da realidade para refletir e encontrar alternativas para os seres humanos, sobretudo para a libertação dos pobres e oprimidos. "Antes de fazer Teologia, é preciso fazer libertação [...]. Trata-se de viver o compromisso da fé, em nosso caso, de participar, de algum modo, no processo libertador, de estar comprometido com os oprimidos". ${ }^{18}$ Nesse caso, a Teologia é sempre um ato segundo, sendo o primeiro a fé que opera pelo amor. ${ }^{19} \mathrm{O}$ ato primeiro é o engajamento na luta por justiça social e libertação para aqueles/as que vivem oprimidos pelo sistema. Parece ser esta a melhor alternativa para se fazer Teologia em tempos de pandemia, conteúdo da próxima seção.

\section{O fazer teológico em tempos de pandemia e pós-pandemia}

Se fazer Teologia já é, por si só, um grande desafio, certamente fazer Teologia em tempos de crise como a que a sociedade vive no momento é

\footnotetext{
${ }^{16}$ ZABATIERO, J. P., Para um método teológico, p. 43.

${ }^{17}$ LIBÂNIO, J. B.; MURAD, A., Introdução à Teologia, p. 64-65.

${ }^{18}$ BOFF, C.; BOFF, L., Como fazer Teologia da libertação, p. 37.

${ }^{19}$ BOFF, C.; BOFF, L., Como fazer Teologia da libertação, p. 38.
} 
muito mais desafiador ainda. Desafiador sim, mas relevante, na busca de se fazer uma leitura equilibrada do momento vivido pela humanidade. Hans Küng entende que "as crises são interrupções nos contextos habituais da vida e do pensamento, de modo que, antes e depois delas o mundo da Igreja e da Teologia já não é mais o mesmo". ${ }^{20}$ Jon Sobrino, por sua vez, lembra que nesses momentos de crise aguda, vividos pela humanidade, a pergunta que está no imaginário das pessoas, mesmo sem ser verbalizada, é: onde está Deus? Segundo Sobrino:

A maior tragédia, em um terremoto ou em qualquer outra situação - não são as perdas materiais, mas a destruição do humano. A maior solidariedade é ajudar a reconstruí-lo. A maior esperança é continuar a caminhar, praticando a justiça e amando com ternura. ${ }^{21}$

Na verdade, o mundo não será mais o mesmo e por isso é indispensável que o processo do fazer Teologia esteja adequado a esse novo momento vivido pela humanidade agora, no auge da pandemia, e depois, no período pós-pandêmico.

Fazer Teologia em tempos de pandemia pode ajudar a entender um pouco melhor o que está acontecendo, porque uma das principais funções da Teologia é fazer uma leitura adequada e interpretar adequadamente a realidade. Pode ajudar na resposta às quatro perguntas existenciais básicas que a filosofia, a psicologia, a pedagogia e outras ciências também fazem: Quem somos? Onde estamos? De onde viemos? O que estamos fazendo aqui e para onde vamos?22 Como a Teologia consegue responder, com um mínimo de satisfação, a essas perguntas, num momento tão crítico vivido pela humanidade?

Diante disso, uma pergunta incomoda: que tipo de Teologia consegue ser mais útil no enfrentamento da pandemia e no pós-pandemia?

João Batista Libânio e Afonso Murad defendem que o fazer teológico deve estar atrelado ao contexto vivido pela humanidade. Eles defendem que:

O conhecimento teológico deve estar eivado de bom-senso, sensibilidade ao drama humano, compaixão. É necessário levar em conta os condicionamentos pessoais, culturais e sociais e acompanhar a discussão

\footnotetext{
${ }^{20}$ KÜNG, H., Teologia a caminho, p. 205.

${ }^{21}$ SOBRINO, J., Onde está Deus?, p. 39.

${ }^{22}$ MORIN, E., Os sete saberes necessários à educação do futuro, p. 47.
} 
contemporânea. Cabe fazer reflexão iluminada pelo crivo da fé cristã, articulando simultaneamente vários saberes. $\mathrm{O}$ cristianismo não tem respostas prontas a todas as perguntas humanas. Mas recebeu a missão de oferecer luzes e critérios que iluminem a descoberta dessas respostas. ${ }^{23}$

$\mathrm{Na}$ esteira do que propõem os destacados teólogos brasileiros, podese imaginar que, para atender as muitas e enormes demandas do contexto pandêmico e pós-pandêmico vivido pela humanidade, e pelo Brasil em particular, é fundamental pensar em Teologias que se enquadrem no perfil abaixo elencado.

Primeiro, é necessário que seja uma Teologia Bíblica, mas que interprete a bíblia de uma maneira aberta e devidamente contextualizada, que leve em consideração os novos estudos bíblicos, descobertas arqueológicas, sem fatalismos nem fundamentalismos. Que seja capaz de "interpretar para o nosso tempo o velho Evangelho e não outro". ${ }^{24}$ Certamente que é nas páginas das Escrituras que serão encontradas as mensagens de conforto, ânimo e esperança para a humanidade num momento tão desafiador para toda a sociedade.

Em segundo lugar, é necessário pensar numa Teologia kenótica, ou seja, que seja humilde para reconhecer que não tem respostas para todas as perguntas, como bem disseram os teólogos acima citados, nem para muitas delas, diante de um tempo de incertezas e obscuridade quanto ao presente e ao futuro da humanidade. Rocha entende que "a kenosis, como categoria filosófica central do pensamento de G. Vatttimo, é o lugar pós-moderno por excelência para a Teologia cristã [...] O pensiero debole permite uma nova relação com a história, percebendo-a em sua condição plural e policêntrica". ${ }^{25}$ Uma Teologia frágil, ou seja, que reconheça a fragilidade humana e sua total dependência de Deus e uns dos outros. Se isso já era necessário antes do início da pandemia, quanto mais agora diante de tantas perdas e dilemas vividos pela humanidade inteira, incluindo aqueles e aquelas que creem num Deus de amor, graça e misericórdia.

O que foi elencado até agora, resulta numa Teologia dialogal, que esteja pronta para dialogar com todos os segmentos da sociedade (outras ciências, autoridades constituídas, instituições organizadas, ONGS, etc), sobretudo com as ciências médicas, pois são tempos de pandemia. Gottfried Brakemeier

\footnotetext{
${ }^{23}$ LIBÂNIO, J. B.; MURAD, A., Introdução à Teologia, p. 218.

${ }^{24} \mathrm{KÜNG}, \mathrm{H}$., Teologia a caminho, p. 207.

${ }^{25}$ ROCHA, A. R., Modos de crer e conhecer, p. 105, 108.
} 
faz um resgate histórico interessante dos conflitos, desencontros e equívocos na relação entre religião e ciência, sobretudo entre a fé cristã e as demais ciências. Equívocos cometidos de ambos os lados, do cristianismo em relação às teorias científicas como também das ciências em relação à pertinência e ao futuro da religião para o bem estar da humanidade. ${ }^{26}$ Feita a análise histórica dos confrontos e dos diálogos entre ciência e religião, Brakemeier aponta um caminho interessante. Ele afirma que "Fé e ciência estão proibidas de confundirse em amálgama indefinido. Há particularidades a respeitar. O que importa é achar uma forma de parceria no compromisso de descobrir, compreender e gerenciar a realidade, que é só uma, embora multidimensional". ${ }^{27}$ Observe-se aí um ponto fundamental nesses tempos de pandemia. A ciência certamente tem um papel preponderante, na busca de vacinas para conter o avanço do novo coronavírus, enquanto procura descobrir medicamentos que sejam cientificamente comprovados no tratamento da doença que atinge milhões de pessoas ao redor do mundo ao mesmo tempo, colapsando os sistemas de saúde e causando a morte de milhares e milhares de pessoas. Isso já aconteceu diante de outras pandemias, tão bem documentado por John M. Barry que, com riqueza de detalhes apresenta todo o dilema de cientistas que lutaram contra $\mathrm{o}$ tempo para conhecer e enfrentar uma das maiores pandemias enfrentadas pela humanidade antes da chegada do novo coronavírus. ${ }^{28}$ Barry enfatiza logo no prólogo de seu livro documentário que se trata de:

Uma história de ciência, de descoberta, de como se pensa e de que modo mudar a maneira como se pensa, de como, em meio ao caos quase absoluto, alguns homens buscaram a frieza da contemplação, a calma absoluta [...] mas que leva a ação severa e determinada. ${ }^{29}$

Um registro meticuloso de cada tentativa, de cada frustração, de cada avanço na busca de soluções, de socorro para a humanidade num momento caótico em todos os sentidos. Segundo Barry:

Foi o primeiro grande choque entre uma força natural e uma sociedade com indivíduos que se recusavam a se submeter a essa força ou a

\footnotetext{
${ }^{26}$ BRAKEMEIER, G., Ciência e religião, p. 9-24.

${ }^{27}$ BRAKEMEIER, G., Ciência e religião, p. 24.

${ }^{28}$ BARRY, J. M., A grande gripe.

${ }^{29}$ BARRY, J. M., A grande gripe, p. 13.
} 
simplesmente implorar por salvação através da intervenção divina, indivíduos determinados a confrontar essa força diretamente, com uma tecnologia em desenvolvimento e suas mentes. ${ }^{30}$

Independente desses confrontos que ocorreram por ocasião da gripe espanhola, detalhadamente registrado por Barry, muitas coisas aconteceram que fizeram ciência e religião reconhecerem a vulnerabilidade, tanto desta como daquela e de outros segmentos da sociedade, e que a parceria e a cooperação deveria ser a melhor saída, muito bem descrita no epílogo de sua extensa obra. ${ }^{31}$

As semelhanças dos dilemas vividos pela humanidade por ocasião da pandemia da gripe espanhola, tão bem documentada por Barry e outros autores, e a pandemia do novo coronavírus são impressionantes e antes mesmo que esta se iniciasse, Barry já previa que, no caso do surgimento de um vírus semelhante ao que causou a gripe espanhola surgir, certamente os avanços experimentados pela medicina e pela sociedade de um modo geral seriam utilizados para amenizar a situação. Mesmo assim, segundo Barry, "dezenas de milhões morreriam e uma grave pandemia de gripe atingiria a humanidade como um tsunami, lotando as unidades de tratamento intensivo (UTI) e adoecendo médicos e enfermeiros, colapsando os sistemas de saúde". ${ }^{32}$ A impressão que se tem é que Barry está descrevendo com antecedência o que estamos vivenciando nesse início de 2021, um ano depois do início da pandemia. Isso requer das autoridades científicas e religiosas a busca do diálogo e do entendimento, como defende Brakemeier: "isso implica a tentativa da conjugação dinâmica dos saberes e do exercício de uma autêntica interdisciplinaridade". ${ }^{33}$

Por sua vez, Zabatiero defende que "deve ser ressaltado o caráter provisório e dialogal de toda elaboração teológica sob o risco de a Teologia transformar-se em letra morta". ${ }^{34}$ Mais do que nunca, é necessário um fazer teológico capaz de conjugar esforços através do diálogo e do entendimento com todos os segmentos da sociedade, incluindo autoridades, tanto políticas como também outras áreas do saber como as ciências médicas, as ciências sociais e humanas.

\footnotetext{
${ }^{30}$ BARRY, J. M., A grande gripe, p. 14.

${ }^{31}$ BARRY, J. M., A grande gripe, p. 502-515.

${ }^{32}$ BARRY, J. M., A grande gripe, p. 503.

${ }^{33}$ BRAKEMEIER, G., Ciência e religião, p. 24.

${ }^{34}$ ZABATIERO, J. P., Para um método teológico, p. 167.
} 
Outro aspecto importante no fazer teológico nesses tempos difíceis de pandemia é o aspecto humanizador da Teologia. É indispensável que se faça uma Teologia humanizadora, que torne as pessoas mais humanas e menos desumanas, diante de uma realidade que tem causado tanta dor e tanto sofrimento por toda a parte, em toda a humanidade. Um fazer teológico que proponha uma sociedade mais humanizada, sintonizada com o projeto do Reino de Deus para os seres humanos e o meio ambiente. ${ }^{35}$ Dentro desse aspecto, indispensável o acento em valores como a solidariedade e o serviço, na busca do atendimento das necessidades básicas das pessoas que perderam seus postos de trabalho, que se tornaram vulneráveis com a doença, que perderam seus entes queridos, que atuam na linha de frente ao combate da pandemia. Aqui, solidariedade, entendida como "ajudar-se mutuamente, aqueles que dão e aqueles que recebem". ${ }^{36}$

Indispensável também que se faça uma Teologia que contemple o ser humano em sua integralidade, que veja o ser humano como um todo: alma, espírito, corpo, emoções, sentimentos, etc., como propõe a Teologia da Missão Integral da Igreja, representada pela Rede Miquéias que envolve projetos de intervenção social no mundo todo.

A missão integral, ou transformação holística, é a proclamação e a demonstração do Evangelho. Não é, simplesmente, que a evangelização e o compromisso social tenham que ser levados a termo juntos. Pelo contrário. Na missão integral, nossa proclamação tem consequências sociais quando convocamos as pessoas ao arrependimento e ao amor em todas as áreas da vida. E o nosso compromisso social tem consequências para a evangelização quando damos testemunho da graça transformadora de Jesus Cristo. Se assumimos uma postura de omissão diante do mundo, traímos a Palavra de Deus, a qual requer de nós que sirvamos ao mundo. Se assumimos uma postura de omissão à Palavra de Deus, não temos nada que oferecer ao mundo. ${ }^{37}$

Eis um momento em que a Teologia não pode se omitir em oferecer ajuda às pessoas, seja através das comunidades de fé, seja através de pronunciamentos de teólogos reconhecidos, seja através das organizações que reúnem instituições teológicas.

${ }^{35}$ MURAD, A., A casa da Teologia, p. 35.

${ }^{36}$ SOBRINO, J., Onde está Deus?, p. 50.

${ }^{37}$ REDE MIQUÉIAS, Declaração da Rede Miquéias sobre Missão Integral, p. 19. 
Outra marca indispensável no fazer teológico em tempos de pandemia é a veracidade. Em meio a tantos desencontros com a divulgação de fake news, é mister que se faça uma "Teologia veraz, não oportunista nem conformista, que dá as razões da própria fé, e é capaz de buscar e exprimir a verdade cristã de modo crível". ${ }^{38}$ Uma Teologia verdadeira, autêntica, sincera, honesta, que não se aproveita desses momentos de crise para explorar a fé e a fragilidade do ser humano.

Uma dimensão da Teologia que não pode ser esquecida nesse momento de crise universal é a dimensão profética. É imperativo que se faça uma Teologia que tenha coragem de denunciar as injustiças, a corrupção, a demagogia política escancaradas pela pandemia. Boaventura de Souza Santos adverte quanto ao fato de que as pandemias não matam tão indiscriminadamente quanto se julga.

É evidente que são menos discriminatórias que outras violências cometidas na nossa sociedade contra trabalhadores empobrecidos, mulheres, trabalhadores precários, negros, indígenas, imigrantes, refugiados, sem abrigo, camponeses, idosos, etc. Mas discriminam tanto no que respeita à sua prevenção, como à sua expansão e mitigação. Por exemplo, os idosos estão a ser vítimas em vários países de darwinismo social. Grande parte da população do mundo não está em condições de seguir as recomendações da Organização Mundial de Saúde para nos defendermos do vírus porque vive em espaços exíguos ou altamente poluídos, porque são obrigados a trabalhar em condições de risco para alimentar as famílias, porque estão presos em prisões ou em campos de internamento, porque não têm sabão ou água potável, ou a pouca água disponível é para beber e cozinhar, etc. ${ }^{39}$

É impossível pensar em fazer Teologia sem o compromisso em denunciar os desmandos que ocorrem na sociedade, seja no desvio de verbas, compras superfaturadas, aumentos abusivos de preços, corrupção dos atores políticos, seja na exploração da pandemia para o aumento do capital político, seja no mau uso do dinheiro público ou na má gestão da crise por parte das autoridades federais, estaduais ou municipais.

Um desafio tão grande, que envolve toda a humanidade, independente de raça, cor, credo, condição social, a pandemia requer que se faça uma

${ }^{38}$ KÜNG, H., Teologia a caminho, p. 235.

${ }^{39}$ SANTOS, B. S., A cruel pedagogia do vírus, p. 23. 
Teologia ecumênica, que conte com a participação de pessoas de diversos credos diferentes, com abordagens diferentes, mas com um objetivo comum que é atender as demandas da humanidade num tempo tão crítico como o que está sendo vivido por ocasião da pandemia. Se o problema é universal, a solução também precisa ser universal, no sentido de ser encontrada na soma dos esforços daqueles e daquelas que pretendem encontrar a saída para a humanidade em tempos tão difíceis.

Muito tempo antes do início da pandemia Hans Kung já preconizava a necessidade da busca de um novo paradigma no fazer teológico, ou seja, uma Teologia ecumênica crítica, que segundo ele precisa ser livre, ou seja não autoritária; crítica, ou seja, não tradicionalista; ecumênica, ou seja não confessional, uma Teologia que considere a outra Teologia não mais como inimiga, e sim como colaboradora. ${ }^{40}$

Ao longo da história, em momentos de crise aguda, como a que vive a humanidade com a pandemia do novo coronavírus, nasceram Teologias que alimentaram esperança no coração do povo. Um exemplo disso foi a Teologia da esperança, articulada pelo teólogo alemão Jürgen Moltmann no contexto da Segunda Guerra Mundial, e exposta no compêndio que recebe o mesmo nome. ${ }^{41}$ A exemplo do que fez Moltmann num momento tão desafiador, de reconstrução, com o término da Segunda Guerra Mundial, o fazer teológico nesses tempos de pandemia precisa exalar esperança e otimismo, reconhecendo que, mesmo diante dos muitos desafios, Deus está no controle da história humana e que havendo união entre os povos, é possível superar a crise e reconstruir a sociedade quando a pandemia terminar.

"Necessidade ou utopia, temos que construir um mundo novo, não simplesmente 're-construir' o antigo. Se não se 'construir' o Terceiro Mundo, todo o planeta estará em perigo", ${ }^{42}$ afirmou Jon Sobrino, comentando os grandes desafios para a reconstrução de El Salvador após os grandes terremotos de 2001.

Por falar em reconstrução, um último aspecto do fazer teológico em tempos de pandemia a ser abordado neste artigo é a proposta de se fazer uma Teologia criativa, que ajude a humanidade a se preparar para um recomeço, para o novo normal, com novas perspectivas, ocupada na construção de um mundo mais humano e mais fraterno. Que ajude a sociedade a tirar lições positivas

\footnotetext{
${ }^{40}$ KÜNG, H., Teologia a caminho, p. 190-191.

${ }^{41}$ MOLTMANN, J., Teologia da esperança.

${ }^{42}$ SOBRINO, J., Onde está Deus?, p. 53.
} 
da pandemia e contribua para a transformação da sociedade. Como assevera Boaventura de Souza Santos "muito provavelmente, quando terminar a quarentena, os protestos e os saques voltarão, até porque a pobreza e a extrema pobreza vão aumentar". ${ }^{43}$ Daí a importância de uma Teologia que aponte caminhos novos para um novo tempo para a humanidade, confiando naquele que disse: "eis que faço novas todas as coisas" (Ap 21,5).

\section{Conclusão}

Certamente não é simples nem fácil fazer qualquer coisa em tempos de pandemia. Neste artigo se procurou apontar algumas possibilidades no que diz respeito ao fazer teológico de tal forma a que a Teologia dê a sua contribuição no enfrentamento da crise vivida pela humanidade em virtude da pandemia do novo coronavírus.

A primeira abordagem foi no sentido de entender o que significa viver em tempos de pandemia, os muitos temores vivenciados pela humanidade e ao mesmo tempo as oportunidades que surgem com a pandemia, mesmo sem planejamento prévio, mas que podem ser encontradas no meio do caminho.

Foram apresentadas algumas pistas dos caminhos que se segue no processo do fazer teológico, de onde se parte, o que se pretende, algo que por si só já é desafiador, uma vez que existe uma pluralidade de métodos utilizados, dependendo da leitura que se faz, a ênfase que se dá e dos objetivos que se tem.

Por fim, foram apresentados alguns ensaios do que pode se constituir a construção de Teologias que podem fazer a diferença na sociedade no período de pandemia e pós-pandemia. Nesse sentido foram apresentadas algumas características indispensáveis nas Teologias que podem ser feitas nesse tempo, ressaltando a importância da Teologia no enfrentamento da crise da pandemia e na construção da nova realidade que será produzida com o fim da mesma.

\section{Referências bibliográficas}

BARRY, J. M. A grande gripe: a história da gripe espanhola, a pandemia mais mortal de todos os tempos. Rio de Janeiro: Intrínseca, 2020.

BASSETS, M. Bruno Latour: "O sentimento de perder o mundo, agora, é coletivo”. El País, Madrid, 31 mar. 2019. Disponível em: <https://brasil.

${ }^{43}$ SANTOS, B. S., A cruel pedagogia do vírus, p. 23. 
elpais.com/brasil/2019/03/29/internacional/1553888812_652680.html>. Acesso em: 21 out. 2020.

BERGER, P. L. A construção social da realidade. Petrópolis: Vozes, 1973.

BERGER, P. L. Rumor de anjos. A sociedade moderna e a redescoberta do sobrenatural. Petrópolis: Vozes, 1997.

BÍBLIA Sagrada. Versão Revista da Tradução de João Ferreira de Almeida. 2. impr. Rio de Janeiro: Imprensa Bíblica Brasileira, 1987.

BOFF, C.; BOFF, L. Como fazer Teologia da libertação. Petrópolis: Vozes, 2010.

BRAKEMEIER, G. Ciência e religião: quem vai conduzir a história? São Leopoldo: Sinodal, 2006.

BROTTO, J. C. P. O eternamente novo no mesmo evangelho: implicações teológico-pastorais para a evangelização das tribos urbanas de rosto underground. Rio de Janeiro, 2016. 212p. Tese. Faculdade de Teologia, Pontifícia Universidade Católica do Rio de Janeiro.

DI CESARE, D. Anche per lo stato d'eccezione la paura è un boomerang. Il Manifesto, Democrazia, 03 mar. 2020. Disponível em: $<$ https://www.c3dem. it/wp-content/uploads/2020/04/anche-per-lo-stato-deccezione-la-paura-è-unboomerang-d.-di-cesare-man.pdf $>$. Acesso em: 21 out. 2020.

DUNKER, C. Coroa de Espinhos. Arte!Brasileiros, 13 abr. 2020. Disponível em: $<$ https://artebrasileiros.com.br/cultura/coroa-de-espinhos-christian-dunkerpeste-coronavirus-saude-mental $>$. Acesso em: 21 out. 2020.

DURKHEIM, É. Da divisão do trabalho social. São Paulo: Martins Fontes, 1999.

KÜNG, H. Teologia a caminho: fundamentação para o diálogo ecumênico. São Paulo: Paulinas, 1999.

LIBÂNIO, J. B.; MURAD, A. Introdução à Teologia: perfil, enfoques, tarefas. São Paulo: Loyola, 2014.

MORIN, E. Os sete saberes necessários à educação do futuro. São Paulo: Cortez; Brasília: UNESCO, 2001.

MOLTMANN, J. Teologia da esperança: estudos sobre os fundamentos e as consequências de uma escatologia cristã. São Paulo: Loyola, 2005. 
MURAD, A. A casa da Teologia: introdução ecumênica à ciência da fé. São Paulo: Paulinas; São Leopoldo: Sinodal, 2010.

REDE MIQUÉIAS. Declaração da Rede Miquéias sobre Missão Integral. In: CHESTER, T. (Ed.). Justiça, misericórdia e humildade: Missão Integral e o pobre. Carlisle: Paternoster, 2002. p. 19.

ROCHA, A. R. Modos de crer e conhecer: relações entre Teologia e epistemologia. Rio de Janeiro: Letra Capital, 2017.

SANTOS, B. S. A cruel pedagogia do vírus. Coimbra: Edições Almedina, 2020. SOBRINO, J. Onde está Deus? Terremoto, terrorismo, barbárie e utopia. São Leopoldo: Sinodal, 2007.

TEIXEIRA, D. B. O novo coronavírus e as ecologias da plantation. IHUNotícias, 18 mar. 2020. Disponível em: <http://www.ihu.unisinos.br/78noticias/597212-o-novo-coronavirus-e-as-ecologias-de-plantation>. Acesso em: 21 out. 2020.

ZABATIERO, J. P. Para um método teológico. São Paulo: Fonte Editorial; Vitória: Unida, 2011.

Valdir Stephanini

Doutor em Teologia pela Pontifícia Universidade Católica do Rio de Janeiro Docente do Programa de Pós-Graduação em Ciências das Religiões da Faculdade Unida Vitória / ES - Brasil E-mail: valdir@fuv.com.br.

Julio Cezar de Paula Brotto

Doutor em Teologia pela Pontifícia Universidade Católica do Rio de Janeiro. Docente da Graduação em Teologia na Faculdade Unida Vitória / ES - Brasil E-mail: julio.brotto@fuv.com.br

Recebido em: 01/03/21

Aprovado em: 14/06/21 